Globus An International Journal of Management \& IT

A Refereed Research Journal

Vol 11 / No 1 / Jul-Dec 2019 ISSN: 0975-721X

\title{
REDESIGNING TRAINING STRATEGY IN BANKS
}

\author{
*Prof (Dr) P.V. Kapoor
}

\begin{abstract}
Indian Banking industry is striving to become competitive in the changing scenario of global integration. To meet the challenges emerging out of the changing conditions the Banks have to ensure that the human resources at their command give their best. Since the strengths of the Banks lies in their human resources, the Bank should strategically plan development of this crucial resources through training and other initiatives. This article elaborates how Banks can systematically plan and implement training in their organization translate employees needs into training programmes and groom employees with an eye on the future.
\end{abstract}

Keywords: Training, Banks, Strategy, India.

\section{Introduction}

The Indian Banking Industry can be categorized into Non-Scheduled banks and Scheduled Banks constitute of Commercial Banks and Co-operative Banks. There are about 67000 branches of Scheduled Banks spread across India. The nationalization of 14 major Banks in 1969 led to a shift from class banking to Mass Banking. Since then the growth of the Banking industry in India has been a continuous process. There are 27 Public-Sector Banks, 31 Private Banks and 29 Foreign Banks.

The Banking Industry in India is undergoing a major transformation due to changes in economic conditions and continuous deregulation making the Banking market extremely competitive with greater autonomy, operational flexibility, and decontrolled interest rate and, liberalized norms for foreign exchange. The market place has been refineded with new rules of the game, with series of innovative product offerings catering to various customer segments. Leading players in Banking Industry are embarking on a series of strategic and tactical initiatives to sustain leadership. These initiatives includes investing in state of the art technology to ensure reliable service delivery and to reduce fixed cost and cost per transaction, innovating products to capture customer mind set, making aggressive forays in the retail advances segments of home and personal loans introduction of centralized core Banking solution which provides the delivery channels like Internet Banking, Mobile Banking etc. It completely automates all operations across all sections in branch and is a step towards paperless office as inside a branch, every counter staff member can handle all type of transactions. Since all CBS (Centralized Core Banking Solution) branches are interconnected, branch customer becomes bank customer. The dimensions of employee's tasks have gone up. The need for training is not only significant but also urgent in the light of the changes taking in the economy.

*Senior Professor (Retd), New Delhi. Email:pvkapoor@gmail.com 
To meet the challenges emerging out of the changing conditions the banks have to ensure that the human resources at their command give their best. The employees today have to keep pace with the trends, forces and factors that affect their operations new skills ideas facts and attitudes are required to cope up with the changes. The employees equipped with new skills and knowledge would face the challenges and handle situations successfully. They would be in a position to integrate new ideas into new set up.

Training increase acceptance of the system and improves performance Banks have to adapt to rapid technological changes, improve quality, increase productivity and enhance new financial products to survive in the competitive markets. Banks have to develop long term perspective to meet he challenges. Lack of training has strong adverse effects on acceptance and performance. The Banks have to ensure that their employees are knowledgeable than just literate. The Banks must realize and believe that employees are its assets and should strive to realize their potential fully. Training should be used as a planned intervention to improve the performance of the individual or the group to achieve the organizational objectives. Training is an approach towards identifying competences, napping of gaps, imparting skills to fill the gaps, measuring results and linking those results to objectives.

Training in the Banking Industry has to be pro-active and continuous process-as an integral part of the organization development. It should continuously take stock of the organizations, objectives in the changing socio-economic, political scenario, fast changing environment increasing work pressures at all levels, diversity of functions and rising clientele expectations. It should envisage synchronization of organization growth with individual development. The training in Banks should help in instilling confidence and determination upto the desired level amongst the participants to make use of the concepts/matters understood/learnt at their back home situation. The training has to create awareness in the individual and group to achieve organizational goals by developing attitudes and approaches suitable to organization environment. The organization training system has to remain in a state of perpetual preparedness to face the challenges posed by environment changes and changing priorities of the Banks.

Complying with ever changing market needs which affect organization's performance is a core human resource function. To enhance the competency of the organization, HR professionals need to realize just how information technology can be useful. This paper focuses on the implementation of technology in the HR functions and identifies the impacts of technology on HRM its opportunities \& challenges and a number of issues on the development \& implementation of information technology systems within HRM. [1]

The organization's ability to assess the business value of information technology investment has been acutely hampered by a dearth of analytical models. Return on Investment (ROI) and Net Present Value (NPV) are often used to calculate the return on IT investments, however, they fail to capture the intangible effects of IT. These intangible effects cannot be ignored since these may sometimes turn an unprofitable investment into a profitable one. This paper aims to presents issues relating to assessment of business value of IT and suggest a framework for such assessment. Further, we illustrate our approach by analyzing it to study the impact of IT investment in State Bank of India. [2, 3, 4]

\section{Training and Development Centre}

Training activities should be looked after by training and developing centre. A separate training and development centre may be established to take care of the training activities. The training centre should provide necessary guidance and support. The training records of all the employers and executives should be maintained in the centre. The entire training record of each employee should be integrated by the training center and provided to Human Resource Development Department/Head of Department when requisitioned. The training centre should maintain schedule of all in-house programme and this should be accessible to all in the bank. The training centre should work in tender with other departments of the Banks and ensure that the training and development programmes match organizations present future needs for effective transfer of learning as well as for performance improvement.

\section{Identify Training Needs}

Each head of department may be advised to identify the competencies of each employees in their department and prepare on the Job Training Plan. The departmental managers should determine what the individual need to learn in order to fulfill their goals and objectives and build the organization they envision/so that these needs may be translated into training programmes. The needs of the individual employees may be identified after taking into account the requirements of both the organization and the individual the employees to the trained to be 
identified on the basis of their experience in the organization.

\section{Training Packages}

Unique training packages are required to be developed and designed to fit individuals. The designing of the training programme should be taken as a special activity. Special training packages may be developed to impart multi skilling and productive work culture among the trainees/ participants. The Banks can partner with academic Institutions or other Training and Development providers in order to create a series of programmes. These programmes should be specially designed for the organization. The training programmes should develop a spirit of innovation in the employee. The programmes should develop a global knowledge of the Banks business and a perspective about the Banks objectives, so that the participants develop a sense of involvement in the corporate objectives and business. The training packages may also be developed and linked with the individual career path activity. The training programmes should be designed for particular target groups keeping their activity areas and the level of experience in the organization with definite objectives.

\section{Course Contents}

The course contents are incorporated in the programmes keeping in mind the needs of the organization, needs of the employees and the understanding of the employees. The course contents should seek to impart knowledge, improve skills and reorient attitude for individual growth and organizational effectiveness. Course contents should help the persons deputed for training to learn new systems and procedures, techniques and ways. It should help in creating participative culture for self growth and organizational excellence. It should also help in brining about the desired attitudinal changes. A number of changes are taking place in the banking field and the staff is not aware of them and is therefore unable to attend to the customer properly. The training system should help the staff members acquire the requisite job knowledge/skills and attitudes.

\section{Faculty}

Adequate emphasis be given on the selection of faculty for the programmes. It is generally felt that the effectiveness of any training programme and the impression that the training process leaves permanently on the trainees depend largely on the proven merit dedication and commitment of the faculty. The experienced senior Manager of the Bank service can be used provided they have aptitude for training and teaching. Lectures by foreign experts associated with the banking Industry can be delivered. Adequate emphasis may be given for faculty development. Faculty members may be deputed to academic institutions for training. This may be encouraged to widen their horizons and for enrichment of job knowledge.

\section{Training Methods}

Training methods should be judiciously matched to achieve an effective blend of lectures, group discussions, case studies, audio-visuals and panel discussions. The modern techniques of learning including the use of educational films mechanical/audio visual should be exploited. Training methods must help in improving personal methods organizational effectiveness.

\section{Nomination}

Employees' development programmes should be made mandatory for every staff member. This will do away with wrong identification and help in achieving the training objectives. The right kind of employees will attend the right kind of training. Whenever the employees are deputed for training and branch managers should brief them suitably and on their return should also discuss with them their gains, from responses to the respective training programmes. It will create a feeling among the employees that the Branch Manager/Head of Department is truly interested in his training and development that trained employees should be placed suitably. This will create faith of the employees in the training system.

While deputing the employees for a particular course, the course objectives and course contents should be kept in mind and the right person be deputed to attend the particular course so that the maximum benefit is derived from the course and wastage is avoided Training should help the person deputed for training. Training to learn new systems and procedures, techniques and ways and at the same timework in teams towards synchronization of organizational growth with individual growth.

Some employees volunteer for certain programmes for reasons other than training and branch managers oblige them that as this relieves them from possible admonition or embarrassment from the controlling authorities in case of not deputation.

The training facilities are at present more utilized by the supervising staff then by the non-supervising staff. Some branch manager avoid deputing 
employees for training programmes as they feel exposure to training makes an employee more cautious and rule bound as the employees tend to quote bank rules, systems and procedures at every step. It may be emphasized that in some training programmes adequate number of participants are not available. Last minute requests are made by the training center to the Branch Managers to send people to training programmes and this results in the obvious "People who could be spared not the needy would be rushed to the programmes."

\section{Timeliness and Duration}

The timelines and duration of the programmes should be reviewed constantly so that the programmes can have relevance and actual impact on the participants. Timeliness in scheduling the programmes is of vital importance, if proper identification of staff is to be ensured. For example employees who are promoted, the training programme should be arranged for them immediately following the promotions. This will give the exposure to the promoted employees of the requisite training in time.

\section{Periodical Renew}

The periodical renew of the trained personnel performance both individually and in the team/unit should be done to renew and reinforce the learnt skills knowledge and their knowledge and their attitudes. This can be done through structural meetings, seminars workshops etc. This will also give feedback about the achievements and limitations of the banks training system.

\section{Conclusion}

The Banks training system should aim at achieving individual growth and organization excellence. Training activity must assume significance in the context of changing market scenario and environmental compulsions. The Bank must initiate steps to update and improve their mechanism for identification of training needs, programme design etc. The Banks staff training centers should introduce new programmes and rationalize some of the existing programmes to cater to the emerging needs and should groom their employees with an eye on the future.

\section{References}

1. Agarwal, Nidhi and Gupta, Ruchika, (2011). "Role of Technology for the Efficiency of
HR Management". Information and Communication Technology: Challenges \& Business Opportunities, (Eds. Avinash Singh, Puneet Kumar and Suresh Kumar) Excel India Publishers, Delhi, 174-176, ISBN: 978-93-81361-00-9.

2. Gupta, Ruchika and Kumar, Puneet, (2013). "Information Technology Business Value Assessment: A Case of State Bank of India". Globus: An International Journal of Management \& IT, 4(2): 30-34, ISSN:0975$721 X$.

3. Agarwal, Nidhi and Naveen, (2016). "A Research Study on Effect on Teacher's Emotional Intelligence and Their SelfEfficiency in Relation to Their Competency". Globus Journal of Progressive Education. 6(2): 1-3, ISSN: 2231-1335.

4. Varma, Siddharth and Gupta, Ruchika, (2016). "Customer Perception \& Behavioral Intention to Use Biometric Enabled eBanking Services in India”. Business Analytics and Cyber Security Management in Organizations, (Eds. Rajagopal and Ramesh Bahl), IGI Gobal Publications, Hershey, PA, 137-146. ISBN13: 9781522509028.

5. Gutpa, Ruchika and Agarwal, S.P., (2017). "A Comparative Study of Cyber Threats in Emerging Economies". Globus: An International Journal of Management \& IT, 8(2): 24-28, ISSN:0975-721X.

6. Agarwal, Nidhi and Jaiswal, Sushma, (2019). "A Study at Organizational Commitment of Educator in School". International Journal of Multidisciplinary Education and Research, 2019, 4(1), 39-41; doi: 10.5281/zenodo.3806468.

7. Agarwal, Nidhi and Jaiswal, Sushma, (2018). "A Study On Job Satisfaction Among Female Teachers". Globus An International Journal of Management \& IT, 9(2), 1380-1382; doi: 10.5281/zenodo.3806127.

8. Agarwal, Nidhi, (2008). "Role of Teacher Educator's towards a Learning Society". Gyanodaya: Journal of progressive Education, 1(1): 60-64; doi: 10.5281/zenodo.3833655. 